leads us to believe that this procedure should be considered to be a mainstream treatment option for the fractured mandibular condyle.

\section{Intellectual Contributions of Authors}

Study concept: Roger Bainton, Douglas Hammond

Drafting and statistical analysis: Douglas Hammond, Adnan Arafat

Manuscript revision: Douglas Hammond

Study supervision: Roger Bainton

\section{CONFLICTS OF INTEREST}

None identified.

\section{Journal scan}

Kotwal RS, Montgomery HR, Kotwal BM, Champion HR, Butler FK Jr, Mabry RL, Cain JS, Blackbourne LH, Mechler KK, Holcomb JB. Eliminating preventable death on the battlefield. Arch Surg 2011 (published online August 15, 2011). doi: 10.1001/archsurg.2011.213.

To evaluate battlefield survival in a novel command-directed casualty response system that comprehensively integrates Tactical Combat Casualty Care guidelines and a prehospital trauma registry, the analysis of battle injury data collected during combat deployments in Afghanistan and Iraq from October 1, 2001 through March 31, 2010 was carried out. All casualties from the 75th Ranger Regiment, US Army Special Operations Command were scrutinised for preventable adverse outcomes and opportunities to improve care. Comparisons were made with Department of Defense casualty data for the military as a whole. A total of 419 battle injury casualties were incurred during seven years of continuous combat in Iraq and 8.5 years in Afghanistan. Despite higher casualty severity indicated by return-to-duty rates, the regiment's rates of $10.7 \%$ killed in action and $1.7 \%$ who died of wounds were lower than the Department of Defense rates of $16.4 \%$ and $5.8 \%$, respectively, for the larger US military population ( $P=0.04$ and $P=0.02$, respectively).

\section{REFERENCES}

1. Boyne PJ. Free grafting of traumatically displaced or resected mandibular condyles. J Oral Maxillofac Surg 1989;47:228-232.

2. Gupta V, Sahoo NK. Extracorporeal fixation of displaced mandibular condylar fracture: viable option. MJAFI 2009;65:229-231.

3. Schneider M, Erasmus F, Gerlach KL, et al. Open reduction and internal fixation versus closed treatment and mandibulomaxillary fixation of fractures of the mandibular condylar process: a randomized, prospective, multicenter study with special evaluation of fracture level. J Oral Maxillofac Surg 2008;66:2537-2544.

4. Davis BR, Powell JE, Morrison AD. Free-grafting of mandibular condyle fractures: clinical outcomes in 10 consecutive patients. Int J Oral Maxillofac Surg 2005;34:871-876.

5. Zide MF, Kent JN. Indications for open reduction of mandibular condyle fractures. J Oral Maxillofac Surg 1983;41:89-98.
Of 32 fatalities incurred by the regiment, none died of wounds from infection, none were potentially survivable through additional prehospital medical intervention, and one was potentially survivable in the hospital setting. Substantial prehospital care was provided by non-medical personnel. The authors of US Army Institute of Surgical Research concluded that a command-directed casualty response system that trains all personnel in Tactical Combat Casualty Care and receives continuous feedback from prehospital trauma registry data facilitated Tactical Combat Casualty Care performance improvements centred on clinical outcomes that resulted in unprecedented reduction of killed-in-action deaths, casualties who died of wounds, and preventable combat death. The authors further stressed that this data-driven approach is the model for improving prehospital trauma care and casualty outcomes on the battlefield and has considerable implications for civilian trauma systems.

Contributed by Col MM Harjai* * Senior Advisor (Surgery and Paediatric Surgery), Command Hospital (SC), Pune - 40. 